\title{
Access Pricing, Bypass and Universal Service in Post
}

\author{
MARK ARMSTRONG * \\ University College London
}

\begin{abstract}
A postal regulator typically faces two issues which make the design of efficient access pricing especially difficult and which complicate the process of liberalizing the industry. First, universal service obligations, together with the presence of fixed costs, require retail prices to depart from the underlying marginal costs of the incumbent provider. Second, competing firms may be able to bypass the incumbent's delivery network. Within a simple and stylized framework, this note analyzes how access charges should best be set in the light of these twin constraints.
\end{abstract}

\section{Introduction and summary}

In an ideal world, a regulated firm's retail prices would be equal to its marginal costs of supply. In such a world, policy towards entry and access pricing is relatively straightforward, as we will see in the analysis that follows. However, for most of the regulated network industries, including post, there are three main reasons why regulated retail prices may diverge from marginal costs. First, the regulated firm may have significant fixed costs, and prices need to be above marginal costs for the firm to be profitable. (Direct transfers to the firm from general taxation revenue are seldom feasible.) Second, the firm has invested in sunk and durable assets, and current prices need to ensure that this investment is compensated adequately (if it was incurred prudently). Otherwise, faith in the regulatory system is eroded and the cost of capital rises to the long-run detriment of consumers. Third, there may be mandated cross-subsidies from one group of users to another, for distributional or political reasons. The obvious example of this last practice in post is the common requirement to offer uniform prices for delivery of specified mail services to virtually all addresses, even though the cost of provision (especially of delivery) varies in different regions. In practice, since retail prices for important services such as basic mail are so visible and politically sensitive, considerations other than pure economic efficiency come into play when these prices are chosen by regulators and

\footnotetext{
* Department of Economics, University College London, Gower Street, London WC1E 6BT, UK. Email: mark.armstrong@ucl.ac.uk. This paper was presented at the conference on "Regulation, competition and universal service in the postal sector", held in Toulouse on March 16-17, 2006. I am very grateful for helpful comments from an editor and referee, as well as from Bruno Jullien, Frank Rodriguez and David Sappington. Research funding from the Economic and Social Research Council (UK) and the Royal Mail is gratefully acknowledged.
} 
politicians. ${ }^{1}$ The same is not as true with access prices, which in this note can be employed for the focused task of ensuring productive efficiency.

Whenever regulated retail prices depart from the incumbent's marginal costs, there will be difficulties with laissez-faire entry (or, when access is required, when the incumbent's access charges are equal to its marginal costs of providing access). In particular, there is a danger of inefficient entry in profitable segments and a danger of a lack of efficient entry in loss-making segments. In addition, there is the funding problem: if cream-skimming entry eliminates profits from hitherto profitable markets, the incumbent may be unable to continue financing its fixed and sunk costs as well as its loss-making universal service operations. Because of these three problems, it is often suggested - not least by the incumbents themselves - that competition and universal service requirements do not mix well, and that liberalization should be curtailed.

Since they have nothing intrinsically to do with the presence of essential inputs and access charges, in Section 2, I discuss these issues assuming that entrants do not need access to the incumbent's delivery network to provide their services. When the incumbent's regulated retail prices diverge from its marginal costs, efficient entry can only be ensured by requiring entrants to pay an output tax equal to the incumbent's profit margin. Depending on the market in question, this profit margin could be positive or negative. In particular, if the incumbent provides a service at a loss (say, letters delivered to rural areas), then efficient entry requires that entrants should receive the same subsidy as the incumbent. When these output taxes are levied (or subsides are granted), an entrant will have an incentive to serve particular market if and only if it is more efficient for it to be the supplier. Such output taxes and subsidies could be collected and paid out within the framework of a carefully-designed universal service fund.

This analysis is then incorporated into a more realistic "vertical" setting in Section 3, where entrants may require access to the incumbent's delivery network to be able to offer their own service. This discussion is divided into situations in which entrants must use the incumbent's network (Section 3.1) and in which entrants have the ability to self-deliver their mail if the incumbent's delivery charge is too high (Section 3.2). In the first case, the output taxes proposed in Section 2 can simply and conveniently be levied via the incumbent's delivery charges, and this results in the so-called "efficient component pricing rule" (ECPR). Here, compared to the output taxes used to finance the universal service fund in Section 2, the incumbent's necessary inputs are an administratively simpler and more robust tax base. In the second case, though, ECPR access charges - which need not be close to the incumbent's actual costs of delivering mail - may induce inefficient bypass of the incumbent's delivery network by entrants. For instance, if the ECPR charge is above the incumbent's cost of delivering an item of mail, then an entrant whose own delivery cost lies between the incumbent's cost and the ECPR charge will prefer to self-deliver, even though it is more efficient for it to employ the incumbent's delivery network. In this case, the regulator ideally needs two instruments: output taxes and cost-based charges for access to the incumbent's delivery network. As in Section 2, the output tax component of this regime can, with care, be implemented via a universal service fund. A theme of the analysis is that regulation can be simplified considerably if the incumbent's retail prices

\footnotetext{
${ }^{1}$ For further discussion on the rationale for universal service policies (in telecommunications), see Riordan (2002) and Chapter 6 of Laffont and Tirole (2000). See Armstrong and Sappington (2006, Sections 3 and 4) for a theoretical account of how distributional and political considerations impact on the choice of regulated prices, as well as on the decision to embark on liberalization itself.
} 
are rebalanced to reflect its underlying costs, to the extent it is politically feasible and permits the incumbent to fund its services.

A brief summary of some related literature goes as follows. To a large extent, this note re-works the telecommunications discussion presented in Armstrong (2001) to be relevant to the postal sector. The analysis is extended somewhat to allow for fixed costs incurred by the incumbent and entrant, and the discussion is expanded at various points. Armstrong (2002, Section 2) extends Armstrong (2001) to allow for product differentiation, several entrants, Ramsey pricing, and bypass which need not be "all-or-nothing", without changing the qualitative insights obtained in the simple setting presented in Armstrong (2001) and this present note.

Laffont and Tirole (2000, pages 118-119) discuss the benefits of imposing output taxes on entrants and note that their use would imply that cost-based access charges are optimal (as confirmed in this note). They suggest that the use of these kinds of taxes is "politically unlikely", but go on to suggest that these taxes could be repackaged as a tax on the whole industry so as to make them seem less discriminatory (again, as is suggested in this note).

Another closely related paper is De Donder (2006), whose analysis is largely complementary to mine. De Donder focuses on the Ramsey approach, where retail and access prices are chosen simultaneously to maximize the regulator's objective. On the other hand, I take the incumbent's retail prices as exogenously fixed in the analysis of the optimal access prices. A second difference is that De Donder considers a wider range of competitive strategies than I do, and in particular, he analyzes "worksharing", where largevolume customers can pre-sort their mail and give it to the incumbent to deliver. Third, De Donder does not consider the use of output taxes as an additional instrument to achieve a good outcome.

\section{Entry and universal service}

Consider a specific postal service offered by an incumbent. Suppose the incumbent incurs a cost $C$ per unit to supply this service, and its quality of service is denoted $U$. $^{2}$ The price for its service is mandated to be $P$ per unit, where, perhaps because of universal service requirements or the need to cover fixed or sunk costs, $P$ is not necessarily close to the cost $C$. Consumer demand for the service is an increasing function of quality net of price, $U-P$. Specifically, suppose consumer demand for the service with quality $U$ and $P$ is $Q(U-P)$, while consumer surplus is $V(U-P)$. To save on notation, suppose that with the price $P$ consumer demand for the incumbent's service is $Q^{*}=Q(U-P)$ while consumer surplus is $V^{*}=V(U-P)$.

There is a potential entrant which can supply its own service that costs $c$ per unit and has possibly different service quality $u{ }^{3}$ The entrant incurs an entry cost $f$ if it chooses to enter this market. This cost $f$ represents the barriers to entry in the market, which are faced by the entrant but not the incumbent. (For instance, the entrant may need to advertise

\footnotetext{
${ }^{2}$ All costs include a reasonable rate of return on capital, hence contain a contribution to "profit" in accounting terms.

${ }^{3}$ The following analysis is not affected if the entrant can choose its service quality $u$, perhaps by changing its fixed and marginal costs. In fact, in this simple framework in which the firm can perfectly extract consumer willingness-to-pay for higher quality, the firm will choose the socially optimal level of quality if it enters.
} 
its presence in a way that the incumbent does not.) The entrant is free to set its price $p$. All consumers will obtain their supplies from the incumbent if $U-P>u-p$, otherwise they will buy from the entrant. Therefore, if it chooses to enter, the entrant will choose its price to equal the "quality adjusted" price of the incumbent:

$$
p=P+[u-U]
$$

In this case, the demand for postal service is unchanged and equal to $Q^{*}$, and consumer surplus is unchanged at $V^{*}$. In sum, total welfare - as measured by the simple sum of consumer surplus and industry profit - is given by

$$
\begin{array}{ll}
V^{*}+(P-C) Q^{*} & \text { with no entry } \\
V^{*}+(P+[u-U]-c) Q^{*}-f & \text { with entry. }
\end{array}
$$

Therefore, entry is efficient if

$$
(u-c) Q^{*}-f \geq(U-C) Q^{*}
$$

But when will entry take place? Given the regulated price $P$, the entrant will set the price (1). Entry is therefore profitable whenever $(P+[u-U]-c) Q^{*}-f \geq 0$, that is, whenever

$$
(u-c) Q^{*}-f \geq(U-P) Q^{*}
$$

Whenever $P$ differs from $C$, therefore, expressions (2) and (3) demonstrate that private and social incentives for entry may diverge.

There are two kinds of market failure, depending on whether the particular service is profitable or loss-making for the incumbent. First, suppose the service is profitable, so $P>C$. If the entrant's characteristics $(u, c, f)$ are such that

$$
(U-C) Q^{*}>(u-c) Q^{*}-f>(U-P) Q^{*},
$$

then entry occurs even though it is inefficient. That is to say, entry can profitably take place when the entrant has higher costs and/or lower service quality than the incumbent. Alternatively, if $P<C$ then whenever

$$
(U-C) Q^{*}<(u-c) Q^{*}-f<(U-P) Q^{*}
$$

it is efficient for entry to take place, yet it is not privately profitable. With a laissez-faire entry policy there is then a potential lack of efficient entry.

At least in theory, it is a straightforward matter to correct this divergence between the private and social incentives for entry, even if the regulator wishes to maintain the noncost-reflective retail price $P$ and does not know the entrant's characteristics $(u, c, f)$. The regulated incumbent can be considered to be paying an output tax equal to 


$$
T=P-C
$$

per unit. (This is positive or negative depending on whether the service is profitable or subsidised.) Efficiency is ensured provided the entrant also pays this tax for each unit it supplies. ${ }^{4}$ This output tax corrects for the difference between the private and social incentives to enter. ${ }^{5}$ Notice this output tax (4) is equal to the incumbent's lost profit - or "opportunity cost" - when it ceases to supply a unit of the specified service. From an efficiency point of view it makes little difference whether the proceeds from the entrant's output tax are paid directly to the incumbent, to the public purse, or into an industry universal service fund. However, if the incumbent has historically been using the proceeds from profitable sectors to finance its fixed or sunk costs or other loss-making activities, then, if the entrant pays the tax to the incumbent or into an industry fund, the incumbent will not face funding problems should entry into profitable markets occur.

While it may seem a little abstract, not to say administratively burdensome, to use these kinds of output taxes to correct for distortions in the incumbent's retail prices, these taxes can sometimes be implemented in a simple and non-discriminatory way via a welldesigned universal service fund. This procedure can be illustrated by means of a simple example, which uses purely illustrative figures, summarized in Table 1. (I return to variants of this example later in the note.)

\begin{tabular}{|l|l|l|}
\hline & urban delivery & rural delivery \\
\hline & & \\
\hline number of letters & $2 \mathrm{bn}$ & $1 \mathrm{bn}$ \\
\hline incumbent's cost per letter & $20 \mathrm{p}$ & $50 \mathrm{p}$ \\
\hline incumbent's stamp price & $30 \mathrm{p}$ & $30 \mathrm{p}$ \\
\hline incumbent's overall profit & $£ 200 \mathrm{~m}$ profit & $£ 200 \mathrm{~m}$ loss \\
\hline & & \\
\hline entrant's contribution to fund per letter & $10 \mathrm{p}$ & $-20 \mathrm{p}$ \\
\hline
\end{tabular}

\section{Table 1: Using a universal service fund to give efficient entry incentives}

Here, the incumbent offers a mail service which is subject to universal service obligations. Letters delivered to rural areas incur a higher cost (50p) compared to letters destined for urban areas (20p). (For now, suppose there are no fixed costs associated with these services.) Its universal service obligation requires the incumbent to offer both services at the same stamp price, $30 \mathrm{p}$, and the firm makes a profit from letters to urban areas that just covers its loss from delivering letters to rural areas.

\footnotetext{
${ }^{4}$ With the tax (4) entry is profitable when $(c+T) Q^{*}+f \leq(P+[u-U]) Q^{*}$, that is, whenever (2) holds, as claimed.

${ }^{5}$ This divergence is most acute when an entrant's service displaces the incumbent's service in a one-for-one manner, as assumed in this note. If instead a unit of the entrant's service displaces only a fraction of a unit of the incumbent's service, then the required output taxes are less sensitive to the incumbent's profit margins. In the limit, if the entrant's service does not displace the incumbent's at all, there is no need to levy output taxes, even if the incumbent's retail prices do not reflect its costs. That is to say, if an entrant supplies an entirely new service which does not affect consumer demand for existing postal services, there is no need to impose an output tax on the entrant. See Armstrong, Doyle and Vickers (1996) for further details.
} 
As discussed, a laissez-faire approach towards entry in this pair of markets will likely lead to (i) inefficient entry into the profitable urban delivery sector, (ii) too little efficient entry into the rural delivery sector, and (iii) funding difficulties for the incumbent in the event of cream-skimming entry into the urban delivery sector. To counter these problems, suppose a universal service fund is set up containing $£ 200 \mathrm{~m}$ to finance rural service provision. The fund is financed by the profit generated in the urban delivery sector, and any firm - entrants and the incumbent - must pay 10p (the incumbent's profit margin in this sector) into this fund for each letter delivered to urban areas. In return, any firm which delivers a letter to a rural area receives a subsidy from the fund equal to $20 \mathrm{p}$ (the incumbent's per-letter loss in that sector). Providing the quantities of letters delivered to the two areas remain largely unchanged with entry, this fund is self-financing, and widespread urban entry does not undermine the ability of the incumbent to serve the lossmaking rural market. More important from an efficiency viewpoint is the feature that the contribution scheme ensures that in each market the entrant has to pay the output tax (4), which gives it the appropriate entry incentives. Therefore, the most efficient firm succeeds in each sector.

To achieve these desirable efficiency properties, it is important that an entrant's contribution to the universal service fund be sensitive to the incumbent's actual profit margins in the markets where entry occurs. For instance, an alternative financing arrangement for the universal service fund may be to require an entrant to make its contribution purely as a proportion of its total revenue, say. Such an arrangement is much simpler from an administrative viewpoint (and perhaps less susceptible to manipulation by an entrant), since only aggregate data from the entrant is needed, not its specific mail volumes in each sector. This arrangement, if suitably designed, can also ensure the incumbent does not run into funding problems if there is cream-skimming entry into its profitable markets. However, this method of financing the universal service fund does not tackle the essential efficiency problems discussed above: the entrant's contributions will not satisfy (4), and there will still be the danger of inefficient entry in the urban market and lack of efficient entry in the rural market.

Suppose next that "rebalancing" of retail prices is politically and administratively feasible. In the numerical example, suppose that the incumbent's retail prices were adjusted so that a letter to urban areas needed a 20p stamp and a letter to rural areas needed a 50p stamp. In this case, there would be no need to set up a universal service fund and a policy of free entry would work well without a tax/subsidy scheme. With basic postal services, though, it seems unlikely that such rebalancing will be politically acceptable in most countries for some time to come. However, policy towards bulk mail - which is used by firms rather than households - is often more flexible in this regard, and there is sometimes scope for pricing which better reflects the underlying costs in this market, a policy which greatly simplifies the liberalisation process. ${ }^{6}$

Another reason why rebalancing is not a panacea is the presence of fixed costs. If its prices reflect only marginal costs, the incumbent cannot recover its total costs. Instead, regulated prices will have to be above marginal costs (at least on average). The presence of price-cost margins can lead to inefficient, cream-skimming entry, just as was seen when

\footnotetext{
${ }^{6}$ For this reason, an incumbent aiming to prevent entry in the long term may argue against substantial rebalancing of its retail prices. When its prices involve large cross-subsidies, the incumbent has a good argument against full liberalization, in that the regulation then required to achieve good outcomes is so complex as to be unrealistic.
} 
cross-subsidies were present. The previous analysis assumed that all costs (20p and 50p in the table) were avoidable. In the case of postal services, in reality a substantial fraction of costs are fixed in nature.

To illustrate the impact of fixed costs, suppose that in addition to the marginal costs presented in Table 1 there is also a fixed cost, joint to the two sectors, equal to $£ 600 \mathrm{~m}$. Since variable costs amount to $£ 900 \mathrm{~m}$ in Table 1, the fixed cost makes up $40 \%$ of the total cost. Suppose first that universal service obligations require a uniform stamp price be set for the two kinds of region. To keep the argument simple, suppose that consumer demand in the two sectors is perfectly inelastic. A uniform stamp price of $50 \mathrm{p}$ is then needed to cover the total cost $£ 1,500 \mathrm{~m}$. In this case, the output tax is increased by $20 \mathrm{p}$ in each region: an entrant should now pay $30 \mathrm{p}$ into the fund for each urban letter it delivers, and pay nothing when it delivers a letter to a rural area. This arrangement ensures that (i) entrants enter only when they are more efficient, and (ii) the incumbent's fixed cost is financed if entry occurs.

Suppose next some rebalancing is feasible. As discussed above, the presence of the fixed cost means that some form of output tax on entrants is required to prevent inefficient cream-skimming entry, no matter how fully the incumbent's prices are rebalanced. However, rebalancing can affect the ease with which a universal service fund is administered. To be concrete, suppose that the incumbent's retail prices are regulated so that there is an equi-proportionate mark-up over the associated marginal costs. In the example in Table 1, the prices which are equally marked-up over costs and which just cover the fixed cost of $£ 600 \mathrm{~m}$ turn out to be $33^{1 / 3} \mathrm{p}$ in the urban sector and $831 / 3 \mathrm{p}$ in the rural sector. This equi-proportionate rule - which is sometimes termed the Allais pricing rule is somewhat ad hoc since it ignores demand elasticity factors which the Ramsey pricing rule incorporates. However, it has the significant advantage that the tax regime for entrants then becomes simple: an entrant should pay a fixed proportion (in this case, $40 \%$, the fraction of fixed costs in total costs for the incumbent) of its total revenue into the industry fund. Thus, rebalancing in this way has the significant advantage that the entrant's output taxes can be deducted from its total revenue, and the detailed pattern of entry in the two kinds of regions does not matter.

\section{Access to the incumbent's delivery network}

Here, I extend the framework in the direction of greater realism so that entrants may require access to the incumbent's delivery network. Specifically, there is a verticallyintegrated incumbent and a potential entrant which may need access to the incumbent's delivery network to be able to compete with the incumbent at the retail level for a specified service (for example, letters delivered to rural destinations). The incumbent incurs a cost $C_{1}$ per unit for providing its end-to-end retail service and a cost $C_{2}$ for providing a unit of delivery service to the entrant. The incumbent's retail service has quality $U$, and it must charge the regulated retail price $P$. In addition, the entrant must pay the incumbent the per-unit access charge $A$ for the latter's delivery service. In Section 3.1, I discuss the case where the entrant requires precisely one unit of the incumbent's delivery access service for each unit of own retail service, and then turn in Section 3.2 to situations where the entrant can selectively bypass the incumbent's delivery network. The first situation is relevant when it is either uneconomic for an entrant to deliver its own mail, or where the incumbent 
holds a legal monopoly over delivering letters. ${ }^{7}$ The second case is often relevant for bulk mail services, if policy permits self-delivery by entrants.

\subsection{No bypass of the incumbent's delivery network}

In this section, I assume that bypass of the incumbent's delivery network is not feasible for the service in question, so that the entrant requires the incumbent to deliver each item of its mail. As before, the entrant's service has quality $u$. When the entrant has access to the incumbent's delivery network, it incurs the additional cost $c$ to provide the retail element of its service. That is to say, the unit cost when the entrant supplies the service is $C_{2}+c$. As before, the entrant also incurs the fixed cost of entry, $f$. Since the entrant will choose its price to be as given in (1), total welfare with and without entry is equal to

$$
\begin{array}{ll}
V^{*}+\left(P-C_{1}\right) Q^{*} & \text { with no entry } \\
V^{*}+\left(P+[u-U]-\left[c+C_{2}\right]\right) Q^{*}-f & \text { with entry. }
\end{array}
$$

Therefore, entry is efficient if

$$
(u-c) Q^{*}-f \geq\left(U-\left[C_{1}-C_{2}\right]\right) Q^{*} .
$$

Similarly to expression (3) above, entry will actually take place when the entrant's margin $[P-A]$ is large enough to satisfy

$$
(u-c) Q^{*}-f \geq(U-[P-A]) Q^{*}
$$

Therefore, from expressions (5) and (6) the private incentive to enter coincides with the social benefit only when $P-A=C_{1}-C_{2}$, or:

$$
A=\underset{\text { cost of delivery }}{C_{2}}+\underset{\text { retail profit }}{P} \overline{2} \xi_{1} .
$$

This formula is an instance of the famous "efficient component pricing rule" (or ECPR) for pricing network access. ${ }^{8}$ This policy requires that the access charge should equal the incumbent's cost of delivering letters, $C_{2}$, plus the optimal output tax in (4) above, which is $T=P-C_{1}$. Since the entrant here is unable to bypass the incumbent's delivery network, a regulator may just as well levy the output tax - which is required to correct for the regulated retail pricing distortions - on the entrant's input, and this is exactly what policy (7) entails. Indeed, since in any access pricing regime the regulator needs to monitor the entrant's use of the incumbent's inputs, it is easier to bundle the

\footnotetext{
${ }^{7}$ In the United States, the incumbent is (broadly speaking) the only firm permitted to access customer mailboxes. See Sidak and Spulber (1996, Chapter 2) for further details.

${ }^{8}$ See Willig (1979) and Baumol (1983) for early discussions of this policy, and Armstrong (2002, Section

2.1) for further analysis and references.
} 
optimal output taxes with access charges rather than to levy them separately. Such a procedure eliminates the need directly to observe entrants' outputs, and so is likely to be easier to implement than the universal service fund outlined in Section 2.

A by-product of the ECPR access pricing policy is that the incumbent's profit in the market in question is not affected by whether or not there is entry. When the access charge is given by (7), the incumbent makes profit $\left(P-C_{1}\right) Q^{*}$ in either event. This implies that when the ECPR policy is followed, the incumbent may have a reduced incentive to lobby against entry, or to artificially degrade or delay the delivery service it offers its rivals. When the access charge is set at a lower level than (7), the incumbent may have an incentive to "sabotage" the entrant by offering an inferior access service. One important advantage of an ECPR policy, therefore, is that it lessens the incumbent's motive to use non-price means to disadvantage its rivals, and so the regulator has less need to undertake detailed and intrusive investigation into the incumbent's non-price behaviour. ${ }^{9}$

We can illustrate this ECPR policy in an extension of the above example, summarized in Table 2. Here, two components are needed to provide an end-to-end mail service: "pick up" and "delivery". ${ }^{10}$ The incumbent is assumed to incur the same pick up cost for all letters but its delivery cost differs in the two kinds of region. The entrant is reliant on the incumbent's delivery network to provide its own mail service.

\begin{tabular}{|c|l|l|}
\hline & urban delivery & rural delivery \\
\hline Incumbent's total cost per letter, of which & $20 \mathrm{p}$ & \\
\hline pick up cost is & $10 \mathrm{p}$ & $50 \mathrm{p}$ \\
\hline delivery cost is & $10 \mathrm{p}$ & $10 \mathrm{p}$ \\
\hline incumbent's stamp price & $30 \mathrm{p}$ & $40 \mathrm{p}$ \\
\hline & & $30 \mathrm{p}$ \\
\hline ECPR access charge for delivery & $20 \mathrm{p}$ & \\
\hline
\end{tabular}

Table 2: The ECPR access charge with no bypass

In this context, the ECPR formula (7) implies the optimal access charge for delivery is $20 \mathrm{p}$ per letter in both regions, which in this example is the geographically-averaged cost of delivery. ${ }^{11}$ With this delivery charge, entry will be profitable only if the entrant has a lower pick up cost than the incumbent (or provides a higher quality service). Notice that the optimal access charge is geographically uniform even though the actual delivery costs vary over the two types of region. The reason for this is that the incumbent's stamp price is uniform and its pick up cost is also uniform. This policy is superior to a cost-based access charging policy, which would require charging for urban delivery at $10 \mathrm{p}$ and charging for rural delivery at $40 \mathrm{p}$. For instance, with an urban delivery charge of $10 \mathrm{p}$ the entrant could have a pick up cost as high as 20p per letter (compared to the incumbent's pick up cost of $10 \mathrm{p})$ and still find entry into that sector to be profitable. And with a rural delivery access charge of 40p no entrant (unless it can offer a hugely higher quality service) could compete against the incumbent's subsidized stamp price of $30 \mathrm{p}$ in that market.

\footnotetext{
${ }^{9}$ See Laffont and Tirole (2000, Section 4.5), for instance.

${ }^{10}$ I assume that the associated sorting costs are included in these two costs.

${ }^{11}$ The fact that the ECPR charge is equal to the geographical average of delivery costs is due to the assumption that the incumbent's services just break even over the two markets. For instance, if the markets run at a loss overall, the ECPR charge would be below the average delivery cost.
} 
It makes little difference to this analysis if the incumbent's delivery costs are largely fixed rather than incurred on a per-letter basis. (Since virtually all addresses are passed by a deliverer each working day, it is plausible that the cost of delivering an extra letter is small.) The ECPR is a "retail-minus" policy, and the access charge is equal to the incumbent's retail price (here, 30p) minus its avoided cost (here, the pick up cost of 10p), and the magnitude of the marginal delivery cost plays no role. Of course, though, the calculation is sensitive to whether the pick up cost element is largely variable or largely fixed in nature.

In sum, when entrants have no realistic scope for delivering letters themselves (either because it is uneconomic, or because regulatory policy forbids this), and when the incumbent's retail prices are regulated, the ECPR formula for pricing access by entrants to the incumbent's delivery network is an appropriate guide for policy. However, there are situations (such as sometimes with bulk mail) where entrants can realistically deliver their own mail, in which case this framework does not apply well. Since the ECPR policy entails access charges which do not accurately reflect the underlying costs, the policy is not always appropriate when an entrant can bypass the incumbent's delivery network. This is the topic of the next section.

\subsection{Allowing for bypass of the incumbent's delivery network}

Suppose now that the entrant can, at a cost, deliver its own mail. As mentioned, this is most likely to apply with bulk mail services. When the entrant does so, suppose that it incurs a $\operatorname{cost} \hat{c}_{1}$ per unit for its end-to-end retail service, and this service has quality $\hat{u}$. (Quality $\hat{u}$ may differ from $u$ if using the incumbent's delivery network degrades or enhances the entrant's service compared to its stand-alone service.) Suppose that the entrant's fixed entry cost when the entrant bypasses the incumbent's delivery network is $\hat{f}$. (Since the entrant will have to invest in additional infrastructure if it is to deliver its own mail, it is plausible that $\hat{f}>f$.) The entrant now has three choices: it can provide the end-to-end mail service itself; it can enter by using the incumbent's delivery network, or it does not enter at all. As in expression (1), the entrant will charge $P+[\hat{u}-U]$ for its end-toend service and $P+[u-U]$ for its service which uses the incumbent's delivery network. Total welfare with these entry strategies is therefore

$$
\begin{array}{ll}
V^{*}+\left(P-C_{1}\right) Q^{*} & \text { with no entry } \\
V^{*}+\left(P+[\hat{u}-U]-\hat{c}_{1}\right) Q^{*}-\hat{f} & \text { with stand-alone entry } \\
V^{*}+\left(P+[u-U]-\left[c+C_{2}\right]\right) Q^{*}-f & \text { with entry via incumbent's network. }
\end{array}
$$

Which regulatory policy ensures the maximum value of welfare in (8) is achieved? Since the relationship between the entrant's inputs and outputs is no longer a fixed one, the regulator will need, if administratively feasible, to use both an access charge and an output tax to attain the best outcome. Indeed, if the regulator can only use the instrument of the access charge $A$, it is quite possible that entry can reduce total welfare (no matter how $A$ 
is chosen). To see this, consider the situation where service qualities are equal $(u=\hat{u}=U)$ and where the entrant's fixed entry costs are zero $(f=\hat{f}=0)$. In this case, total welfare decreases whenever the unit cost of supply increases. Suppose the entrant's costs satisfy

$$
P>\hat{c}_{1}>C_{1} ; c>\left[C_{1}-C_{2}\right]
$$

In this case, unit supply costs must rise with entry, no matter what access charge is chosen. (Since $P>\hat{C}_{1}$, when there is no output tax there will certainly be entry of some form. Since $\hat{c}_{1}>C_{1}$, stand-alone entry will raise costs. And since $c>\left[C_{1}-C_{2}\right]$, entry via the incumbent's network will also raise costs.) Therefore, entry by this firm will reduce welfare. $^{12}$

When the regulator can use both an output tax and an access charge, it is possible to design policy so that entry occurs only when it is socially desirable. Moreover, when entry does occur, the entrant will choose the optimal mode of entry: stand-alone entry or relying on the incumbent's delivery network. ${ }^{13}$ To see this, suppose regulatory policy requires the entrant to pay a tax $T$ per unit of its output and a charge $A$ to the incumbent when the latter delivers a unit of the former's service. The entrant's profit when it supplies the endto-end service itself is then

$$
\left(P+[\hat{u}-U]-\left[T+\hat{c}_{1}\right]\right) Q^{*}-\hat{f} .
$$

The entrant's profit if it instead employs the incumbent's delivery network is

$$
(P+[u-U]-[T+A+c]) Q^{*}-f .
$$

Therefore, given that entry takes place, by comparing expressions (9) and (10) we see that the entrant will choose to use the incumbent's delivery network whenever

$$
A Q^{*} \leq\left([u-\hat{u}]+\left[\hat{c}_{1}-c\right]\right) Q^{*}+[\hat{f}-f]
$$

On the other hand, given that entry occurs, expression (8) implies welfare is higher when the entrant uses the incumbent's delivery network whenever

\footnotetext{
${ }^{12}$ The numerical simulations in De Donder (2006) confirm that entry can be worse for welfare than monopoly, even when the access charge is chosen optimally. (See his Table 1.) See Armstrong, Doyle and Vickers (1996) and Armstrong (2002, Section 2.4.2) for further discussion of the case where the access charge is the only instrument available. In general, since the access charge has to perform two tasks a compromise must be made, and a degree of productive inefficiency necessarily results.

${ }^{13}$ The focus of this note is on the situation where the incumbent's retail price is fixed exogenously. In the alternative Ramsey situation, where retail prices are chosen simultaneously with access charges, the same basic dichotomy which is described in this note also holds. That is to say, if the regulator can use an access charge and an output tax, it is still optimal to use the access charge to give entrants the efficient make-or-buy decisions, that is, to set $A=C_{2}$. (See Armstrong, 2002, Section 2.5.2 for further discussion.) This is an instance of the general point that productive efficiency is desirable when enough tax instruments are available - see Diamond and Mirrlees (1971).
} 


$$
C_{2} Q^{*} \leq\left([u-\hat{u}]+\left[\hat{c}_{1}-c\right]\right) Q^{*}+[\hat{f}-f]
$$

Therefore, given that entry takes place, private and social incentives for the entrant to use the incumbent's network are brought into line by choosing the access charge to equal the incumbent's cost of delivering a unit of service, so that $A=C_{2}$. Making the access charge equal to the incumbent's cost of providing delivery service gives the entrant the appropriate price signal about whether to use or to bypass the incumbent's delivery network.

Turning next to the appropriate choice for the output tax, following the previous discussion in Section 2, the ideal output is $T=P-C_{1}$ per unit, as in expression (4). With these choices for $A$ and $T$ we see that the entrant's profit under each of its three options for entry are:

with no entry

$$
\begin{array}{ll}
\left([\hat{u}-U]+\left[C_{1}-\hat{c}_{1}\right]\right) Q^{*}-\hat{f} & \text { with stand-alone entry } \\
\left([u-U]+\left[C_{1}-c-C_{2}\right]\right) Q^{*}-f & \text { with entry via incumbent's network. }
\end{array}
$$

Comparing these profits with social welfare in (8) we see that the entrant's private incentives are now in line with welfare: the entrant will enter the market when it is socially optimal for it to do so, and if it does enter it will use the incumbent's delivery network whenever it is efficient to do so.

We summarize this discussion by recording that the optimal policy in this situation is for the regulator to set the access charge and the output tax to be respectively:

$$
A=C_{2} ; T=P-C_{1} .
$$

An alternative way to present this policy is to say that when entry occurs: (i) if the entrant uses the incumbent's delivery network it pays the ECPR access charge (7) for this service and there is no output tax, and (ii) if the entrant does not use the incumbent's delivery network, it must pay the output tax (4).

Unlike the situation in Section 3.1, here it is important whether the incumbent's delivery costs are avoidable or not. To give the entrant the correct incentive to use the incumbent's delivery network, the access charge should be set equal to the incumbent's marginal (or avoidable) cost of delivery. If the delivery network is largely a fixed cost, so that $C_{2}$ is small, it is likely to be efficient for an entrant to utilize the same delivery network. 
The output tax element of this regulatory policy can again be implemented by means of an industry universal service fund. For now, suppose that the incumbent incurs no fixed costs, and all its relevant costs are as reported in Table 3.

\begin{tabular}{|c|l|l|}
\hline & urban delivery & rural delivery \\
\hline & & \\
\hline incumbent's total cost per letter, of which & $20 \mathrm{p}$ & $50 \mathrm{p}$ \\
\hline pick up cost is & $10 \mathrm{p}$ & $10 \mathrm{p}$ \\
\hline delivery cost is & $10 \mathrm{p}$ & $40 \mathrm{p}$ \\
\hline incumbent's stamp price & $30 \mathrm{p}$ & $30 \mathrm{p}$ \\
\hline & & \\
\hline entrant's contribution to fund per letter & $10 \mathrm{p}$ & $-20 \mathrm{p}$ \\
\hline incumbent's access charge for delivery & $10 \mathrm{p}$ & $40 \mathrm{p}$ \\
\hline
\end{tabular}

Table 3: Giving appropriate entry and bypass incentives

Here, there is a universal service fund that operates just as in Table 1: a firm sending mail to an urban address must contribute 10p to this fund, and a firm sending mail to a rural address can receive $20 \mathrm{p}$ from the fund. In addition to these contributions, the entrant can gain access to the incumbent's delivery network at actual cost (not the geographically averaged cost as in Table 2). ${ }^{14}$ Notice that if the entrant uses the incumbent's delivery network, its total payment is the ECPR charge of 20p per letter for both kinds of destinations, just as in Table 2. However, the advantage of splitting the ECPR charge into two elements - a cost-based access charge together with an output tax - is that when selfdelivery by entrants is a possibility it is undesirable to make the incumbent's delivery access charges deviate from the incumbent's delivery costs, since that policy invites inefficient bypass of the incumbent's delivery network.

In particular, consider the possible problems which arise if the ECPR price (7) was used as a basis for policy, without the use of output taxes. In the example, this would mean that the incumbent be required to deliver all letters from entrants for a charge of $20 \mathrm{p}$ per letter. For letters destined for rural locations, this subsidized charge means that an entrant can successfully compete against the incumbent if its pick up cost is no greater than 10p, and this outcome is efficient. ${ }^{15}$ For letters destined for urban locations, however, the inflated access price will tempt some entrants to deliver their own letters. This could well be inefficient. For instance, an entrant may have a urban delivery cost as high as $20 \mathrm{p}$, as compared to incumbent's delivery cost of $10 \mathrm{p}$, and still prefer to deliver the letters itself. In addition to this danger of inefficient bypass, there remains the funding issue that the incumbent may be unable to continue funding its loss-making operations if its profits are eroded by cream-skimming entry. If the incumbent's access charges are regulated according to the ECPR policy (without output taxes being imposed on entrants), then the

\footnotetext{
${ }^{14}$ These cost-related delivery charges are sometimes termed zonal access charges. With the (perhaps rather extreme) numbers in this example, the rural access charge of 40p is actually above the uniform retail stamp price of 30p (assumed to continue for single-item services), and so an entrant in the bulk mail service would be better off simply "re-mailing" its rural mail in the incumbent's street mail boxes than using the cost-based access product.

15 One potential downside, however, is that an entrant could have a rural delivery cost of 30p say (as compared to the incumbent's cost of 40p), and still prefer to use the incumbent's network. That is to say, there is scope for lack of efficient bypass with such a policy.
} 
regulator must find some other mechanism to limit the danger of inefficiency posed by selective bypass of the incumbent's delivery network.

The intricate regulation illustrated in Table 3 can be greatly simplified if the incumbent's retail prices for the specified service were rebalanced to reflect its underlying costs. For instance, in the context of Table 3, if the incumbent offered retail prices $20 \mathrm{p}$ and $50 \mathrm{p}$ respectively for urban and rural mail services, the optimal policy is simply for entrants to have access to the incumbent's delivery network at actual cost (respectively, 10p and $40 \mathrm{p}$ ) and the need for a universal service fund is avoided. Full rebalancing allows the regulator to use access charges for the focused task of ensuring that entrants make appropriate bypass decisions to achieve productive efficiency.

However, this convenient conclusion cannot so easily be made if there are significant fixed costs, in addition to the variable costs presented in Table 3. Nevertheless, regulation can still be simplified somewhat. Suppose, as discussed at the end of Section 2, the incumbent incurs a fixed cost of $£ 600 \mathrm{~m}$ to serve these two sectors. To fund this fixed cost, suppose there is an equi-proportionate mark-up of retail prices over marginal costs, which with inelastic demand entails retail prices of $33^{1 / 3}$ p and $83^{1 / 3}$ p per item for urban and rural services if the incumbent is to break even. In this case, a policy of charging entrants for delivery at marginal cost is problematic. If an entrant can use the incumbent's delivery network at marginal cost (10p and 40p respectively), and no output taxes are levied, it could be much less efficient than the incumbent in the pick-up segment, and still find it profitable to enter given the incumbent's high retail prices. In addition to the inefficiency of this outcome, the incumbent will find it impossible to finance its fixed cost if widespread cream-skimming entry occurs. Therefore, ideally an output tax continues to be required, even though retail prices are rebalanced, in order to ensure that only efficient entry occurs and that the incumbent's fixed costs are financed. However, as in Section 2, since price/cost markups are equal in the two regions, the entrant need only pay its output taxes as a simple proportion (in this case, $40 \%$ ) of its total revenues, and there is no need to monitor the entrant's outputs in the two regions at a disaggregated level. If output taxes are not administratively feasible, then some other means needs to be found to prevent inefficient cream-skimming entry.

\section{Conclusions}

This note is intended to provide a simple and tractable framework for discussing access pricing in the postal sector. While the model is too stylized to be a reliable guide to detailed practical policy, it serves to illuminate some of the basic trade-offs which exist for regulatory policy. A richer framework may show the need to consider other factors, but it is hard to see how the issues highlighted here can be avoided in any sensible approach to liberalizing the postal sector.

In Section 3.1, I argued that the appropriate delivery charge was the ECPR charge, at least for those services where entrants cannot bypass the incumbent's delivery network. Such a delivery charge gives entrants the correct signal about whether to enter, with the result that a market is served by the more efficient firm. Such a charge also serves to maintain the revenues needed to fund the incumbent's fixed costs and/or loss-making services. In Section 3.2, I discussed how problems emerge with this policy when entrants can deliver their own mail. The ECPR policy may mean that for some services the 
incumbent's delivery charge is substantially above the associated cost, and in these cases an entrant may decide to deliver its own mail even if its cost of doing so is substantially above the incumbent's. Such an outcome is both inefficient and erodes the incumbent's ability to fund its other services. Therefore, when bypass is possible regulators should be sympathetic to the principle of cost-reflective access charges, especially if the associated retail prices are also cost-reflective. If the incumbent's retail prices cannot be fully rebalanced to reflect marginal costs (for example, because of universal service constraints or because retail prices must cover fixed costs of operation), to achieve good outcomes the regulator will need to use some form of output tax for entrants. Carefully designed output taxes give appropriate signals for efficient entry, and they also serve to contribute to the financing of the incumbent's fixed costs and/or universal service subsides.

\section{$5 \quad$ References}

Armstrong, M. (2001) "Access Pricing, Bypass and Universal Service," American Economic Review, 91: 297-301.

Armstrong, M. (2002) "The Theory of Access Pricing and Interconnection," in M. Cave, S. Majumdar, and I. Vogelsang (ed.), Handbook of Telecommunications Economics: Volume I, North-Holland, Amsterdam.

Armstrong, M., C. Doyle, and J. Vickers (1996) "The Access Pricing Problem: A Synthesis," Journal of Industrial Economics, 44: 131-150.

Armstrong, M., and D. Sappington (2006) "Regulation, Competition and Liberalization," Journal of Economic Literature, 44: 325-366.

Baumol, W. (1983) "Some Subtle Issues in Railroad Regulation," International Journal of Transport Economics, 10: 341-355.

De Donder, P. (2006) "Access Pricing in the Postal Sector: Theory and Simulations," Review of Industrial Organization, 28: 307-326.

Diamond, P., and J. Mirrlees (1971) "Optimal Taxation and Public Production: I Production Effciency," American Economic Review, 61: 8-27.

Laffont, J.-J., and J. Tirole (2000) Competition in Telecommunications. MIT Press: Cambridge, MA.

Riordan, M. (2002) “Universal Residential Telephone Service," in M. Cave, S. Majumdar, and I. Vogelsang (ed.), Handbook of Telecommunications Economics: Volume I,. NorthHolland, Amsterdam.

Sidak, J. G., and D. Spulber (1996) Protecting Competition from the Postal Monopoly. AEI Press, Washington, DC. 
Willig, R. (1979) "The Theory of Network Access Pricing," in H. Trebing (ed.), Issues in Public Utility Regulation, Michigan State University Press, East Lansing, MI. 